\title{
Núcleo de Pesquisa em Informática na Educação - NIE
}

\author{
Breno Fabrício Terra Azevedo ${ }^{1}$, Adelson Siqueira Carvalho ${ }^{1}$ \\ ${ }^{1}$ Instituto Federal de Educação, Ciência e Tecnologia Fluminense - Rua Dr. Siqueira, \\ 273 - Parque Dom Bosco - CEP 28030-130 - Campos dos Goytacazes - RJ - Brasil \\ bterra@iff.edu.br, acarvaleiff.edu.br
}

\section{Nome do Grupo}

Núcleo de Pesquisa em Informática na Educação (NIE).

\section{Objetivos}

O Núcleo de Pesquisa em Informática na Educação tem como objetivo principal desenvolver pesquisa aplicada ao processo de ensino e aprendizagem de diferentes áreas do conhecimento, auxiliada por Tecnologias da Informação e Comunicação, bem como atender a demandas específicas do IFFluminense, tais como: suporte à prática docente, auxílio de professores e funcionários na utilização de softwares educativos, com foco na educação presencial e à distância.

\section{Instituições participantes}

Instituto Federal de Educação, Ciência e Tecnologia Fluminense.

\section{Pesquisadores envolvidos}

Adelson Carvalho, André Uebe, Arilise Lopes, Breno Terra, Eliane Vigneron, Gilmara Barcelos, Helvia Bastos, Maria Letícia Leite, Maurício Amorim, Ricardo Barcelos, Rodrigo Garrett, Rogério Avellar, Silvia Batista, Suzana Macedo.

\section{Principais projetos (em andamento) e fomentos recebidos}

Algumas das bolsas de iniciação científica disponibilizadas aos alunos são provenientes do IFFluminense e outras do CNPq. Os principais projetos (em andamento) do NIE são: Análise automática de fóruns de discussão; Uso de softwares de simulação na experimentação e na resolução de problemas interdisciplinares; Site de apoio ao ensino de eletromagnetismo usando objetos de aprendizagem em realidade aumentada; Estudos e implantações para aprimoramentos de funcionalidades interacionais para o ambiente virtual de aprendizagem colaborativa Rede de Saberes Coletivos (RESA); Produção e divulgação científica de materiais digitais em espaços não formais de aprendizagem: vislumbrando possibilidades; Reusabilidade de objetos e tecnologias de aprendizagem; ECA - Experimentos em Controle e Automação; Desenvolvimento de objetos de aprendizagem digitais acessíveis para alunos com deficiência visual; Integração de software de mineração de texto na plataforma Moodle; Um objeto de aprendizagem de apoio à resolução de problemas interdisciplinares; Aprendizagem com dispositivos móveis; Desenvolvimento de objetos de aprendizagem em realidade aumentada para visualização de campos magnéticos; Desenvolvimento de um site de apoio ao ensino de eletromagnetismo que possibilite visualização e interação com os campos magnéticos. 